\title{
Net community production of oxygen derived from in vitro and in situ 1-D modeling techniques in a cyclonic mesoscale eddy in the Sargasso Sea
}

\author{
B. Mouriño-Carballido ${ }^{1, *}$ and L. A. Anderson ${ }^{1}$ \\ ${ }^{1}$ Applied Ocean Physics and Engineering Department, Woods Hole Oceanographic Institution, Woods Hole, \\ MA 02543-1541, USA \\ *now at: Departamento de Ecoloxía e Bioloxía Animal, Universidade de Vigo, Vigo, Pontevedra, 36200, Spain
}

Received: 10 March 2009 - Published in Biogeosciences Discuss.: 25 March 2009

Revised: 6 August 2009 - Accepted: 7 August 2009 - Published: 26 August 2009

\begin{abstract}
It has been proposed that the disagreement traditionally reported between in vitro incubation and in situ estimates of oxygen net community production (NCP) could be explained, at least partially, by undersampling episodic pulses of net autotrophy associated with mesoscale dynamics. In this study we compare in vitro incubation estimates of net community production with in situ estimates, derived from oxygen profiles and a 1-D model, within a cyclonic eddy investigated in the Sargasso Sea in summer 2004. The in vitro NCP rates measured at the center of the eddy showed a shift from net autotrophy $\left(7 \pm 3 \mathrm{mmol} \mathrm{O}_{2} \mathrm{~m}^{-2} \mathrm{~d}^{-1}\right)$ to net heterotrophy $\left(-25 \pm 5 \mathrm{mmol} \mathrm{O}_{2} \mathrm{~m}^{-2} \mathrm{~d}^{-1}\right)$ from late June to early August. The model-derived NCP rates also showed a temporal decline ( $19 \pm 6$ to $-3 \pm 7$ and $11 \pm 8 \mathrm{mmol}$ $\mathrm{O}_{2} \mathrm{~m}^{-2} \mathrm{~d}^{-1}$ ), but they were systematically higher than the in vitro estimates and reported net autotrophy or balance for the sampling period. In this comparison episodic pulses in photosynthesis or respiration driven by mesoscale eddies can not explain the discrepancy between the in vitro and in situ estimates of NCP. This points to methodological artefacts or temporal or submesoscale variability as the mechanisms responsible for the disagreement between the techniques, at least in this dataset.
\end{abstract}

\section{Introduction}

Net community production (NCP), the difference between gross primary production (GPP) and total respiration (R),

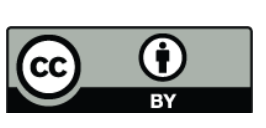

Correspondence to:

B. Mouriño-Carballido

(bmourino@uvigo.es) constitutes a crucial term for comprehending the role of the marine biota as source or sink for $\mathrm{CO}_{2}$. An excess of photosynthesis over respiration ( $\mathrm{NCP}>0$ ), called net autotrophy, implies a net synthesis of organic carbon that can be exported to the deep ocean or to higher trophic levels. A negative balance $(\mathrm{NCP}<0)$, called net heterotrophy, indicates a net consumption of imported or in situ organic carbon. Under the Redfield approximation, in which autotrophic and heterotrophic processes use the same stoichiometric equation, $\mathrm{NCP}$ and new production (the fraction of primary production fuelled by externally supplied nitrogen) should be equivalent (Eppley and Peterson, 1979). Thus NCP is also of interest as an indicator of either nitrate uptake, nitrogen fixation, atmospheric deposition or a difference between autotrophic and heterotrophic stoichiometries, i.e. non-Redfield behavior.

In recent years numerous studies have been conducted to determine the metabolic state of subtropical regions. Measurements of instantaneous oxygen production and respiration rates by in vitro bottle incubations indicate net oxygen consumption, or heterotrophy, in the sunlit zone prevailing throughout large areas (Duarte et al., 2001; Robinson et al., 2002; Williams et al., 2004), whereas in situ geochemical budgets estimate that the upper layer of the ocean is a net source of oxygen (Emerson et al., 2008; Najjar and Keeling, 2000; Riser and Johnson, 2008).

The two approaches differ in their space and time scales, and there are obvious problems in relating measurements made over a few hours in small volumes of water with the geochemical approach, which integrates over larger temporal and spatial scales. It has been proposed that the measured net heterotrophy could be an artifact of undersampling increases in oxygen concentration associated with episodic

Published by Copernicus Publications on behalf of the European Geosciences Union. 
pulses of net community production (Karl et al., 2003). One of the proposed mechanisms that could generate pulses in the balance between photosynthesis and respiration is associated with mesoscale ( $\geq 30 \mathrm{~km}, \geq 30$ days) and submesoscale $(<30 \mathrm{~km},<30$ days) processes (Maixandeau et al., 2005; Mouriño-Carballido, 2009; Nicholson et al., 2008).

In vitro experiments are open to criticism because, by containing water samples, the plankton assemblage may behave differently than free-living organisms (Fernandez et al., 2003; Moran et al., 2007; Sherr et al., 1999). Determining net community production by measuring oxygen changes in situ relies on the ability to sample consistently within the same water mass and to account for non-biological processes that can alter oxygen concentration. Depending on the time-scale, these processes could include air-sea exchange, vertical mixing and advective processes. A few studies attempted to reconcile mass balance and in vitro determinations of carbon primary production (Chipman et al., 1993) and carbon, nitrogen and phosphorous budgets (Rees et al., 2001). Williams and Purdie (1991) compared primary production rates determined in the central North Pacific from in vitro and in situ changes in dissolved oxygen over periods of 12 and $24 \mathrm{~h}$, respectively. The two approaches compared favorably, however neither loss of oxygen to the atmosphere nor a gain from the sub-surface oxygen maximum were considered.

Mesoscale eddies offer a great opportunity for geochemical approaches because of their discrete nature and reduced exchange with adjacent water masses (Rees et al., 2001). As far as we know, the direct comparison between Lagrangian in vitro and in situ determinations of oxygen net production inside mesoscale features has not been tried so far. A cyclonic eddy C1 was intensively investigated in the Sargasso Sea during four cruises carried out in summer 2004. Measurements of net community production (NCP) and respiration (R) based on in vitro changes in oxygen evolution were conducted during two of the four cruises (Mourino-Carballido and McGillicuddy, 2006). In order to investigate if undersampling of enhanced NCP within mesoscale eddies could explain at least part of the disagreement previously reported between in vitro and in situ techniques, we used a 1-D model to: 1) compare in vitro and in situ estimates of oxygen NCP in the cyclonic eddy $\mathrm{C} 1$, and 2) estimate the relative contribution of biological and physical processes to the changes in oxygen concentration observed at the eddy center through the sampling period.

\section{Methods}

\subsection{In situ observations from EDDIES 2004 summer cruises}

Four oceanographic cruises (OC404-1, 11 June-3 July 2004; WB0409, 24 June-2 July 2004; OC404-4, 25 July-12 Au-
Table 1. Details for mean vertical profiles at eddy center used as model initial and final conditions. MLD is mixed layer depth.

\begin{tabular}{lllll}
\hline & 21-22 June & 1 July & 27-28 July & 3-4 August \\
\hline Cruise & OC404-1 & WB0409 & OC404-4 & WB0413 \\
CTD stations & 18,20 & 25 & $5,7,18,19$ & $2,3,4,5$ \\
Mean yearday & 172.9 & 182.9 & 209.0 & 216.0 \\
MLD (m) & 9.8 & 4.1 & 19.8 & 25.3 \\
\hline
\end{tabular}

gust 2004 and WB0413, 2-11 August 2004) were conducted on board the R/V Oceanus (OC) and Weatherbird II (WB) to study the temporal evolution of biogeochemical properties in the cyclonic eddy $\mathrm{C} 1$ centered at ca. $30.5^{\circ} \mathrm{N} 64.7^{\circ} \mathrm{W}$. Meteorological data including wind speed and shortwave radiation flux were collected with an improved meteorological (IMET) sensor package. Conductivity-temperature-depth (CTD) profiles were obtained with a SeaBird 911 and a SeaBird 43 attached to a rosette equipped with Niskin bottles. Samples were collected on each CTD cast for the determination of nitrate + nitrite (DNN), oxygen and chlorophyll-a concentrations. Methods for nitrate, oxygen and chlorophyll determinations are described in Knap et al. (1993). Oxygen concentrations determined by the Winkler technique were used to calibrate the CTD oxygen sensors. Experiments to determine NCP, R and Gross Primary Production (GPP) from in vitro changes in dissolved oxygen during 24-h light/dark bottle incubations were carried out at $\mathrm{C} 1$ center during OC4041 (st 20) and OC404-4 (st 50) cruises. Samples were incubated for $24 \mathrm{~h}$ in a light and temperature-controlled ondeck incubator. Averaged standard deviation (STD) of incubator temperature from the in situ temperature for each experiment was $<0.5^{\circ} \mathrm{C}$. Detailed methods for oxygen in vitro experiments are described in Mouriño-Carballido and McGillicuddy (2006).

\subsection{Model description}

The location of eddy center as a function of time was estimated from a combination of Sea level Anomaly (SLA), expendable bathythermograph (XBT) and Acoustic Doppler Current Profiler (ADCP) data (McGillicuddy et al., 2007). Of the CTD stations within $20 \mathrm{~km}$ of this estimated location, stations were chosen as representing eddy center based on their temperature and salinity (T-S) properties and the vertical displacement of their main and seasonal thermoclines (Table 1, Fig. 1). Data profiles within four different 48-h periods were horizontally averaged into mean profiles. From these, the time-mean depth-dependent NCP rates were estimated within the three intervening time intervals as follows. First a 1-D data assimilation physical model was used to estimate the vertical diffusivity $\kappa(z, t)$ and the vertical velocity $w(z, t)$ from the evolution of observed temperature profiles, where $z$ and $t$ are depth and time respectively. These $\kappa$ and 

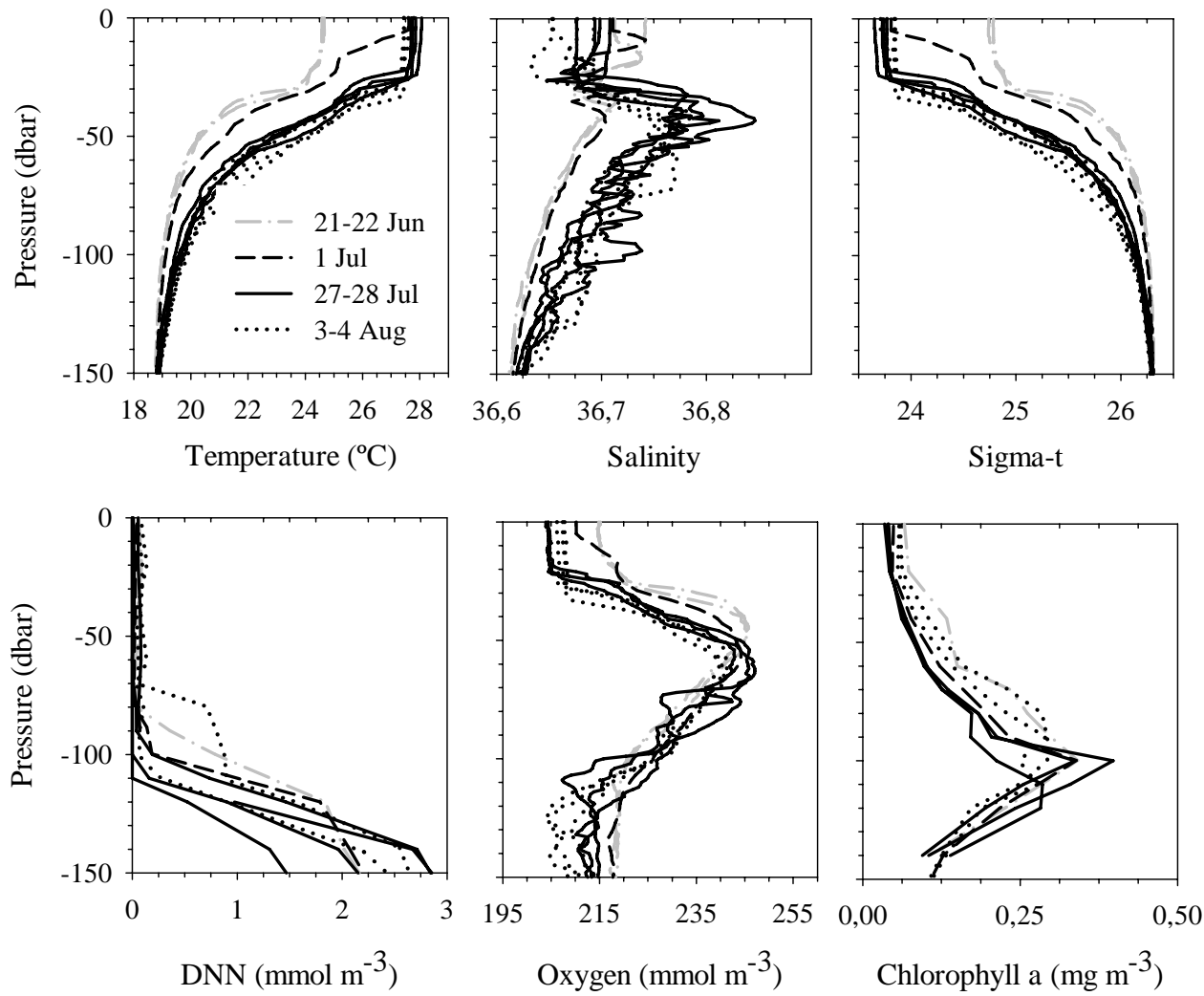

Fig. 1. Vertical distribution of temperature, salinity, sigma-t, nitrate + nitrite (DNN), oxygen and chlorophyll a concentration at the stations selected for the 1-D simulations at the center of cyclonic eddy C1 on 21-22 June (OC404-1, st 18 \& 20), 1 July (WB0409, st 25), 27-28 July (OC404-4; st 5, 7, 18 \& 19) and 3-4 August (WB0413; st 2, 3, 4 \& 5).

$w$ estimates were then used in a 1-D data-assimilation oxygen model to estimate NCP rates from the evolution of observed oxygen profiles. The 1-D model grid extended from 0 to $150 \mathrm{~m}$ at $1 \mathrm{~m}$ resolution. The bottom boundary was set at $150 \mathrm{~m}$, where temporal changes and horizontal and vertical gradients in the data are very small (Fig. 1), to minimize sensitivity to the bottom boundary condition. Adams-Bashforth timestepping and a timestep of 0.0005 days were used.

\subsubsection{Physical model}

The following model was used to iteratively optimize $\kappa(z, t)$ and $w(z, t)$ from two observed vertical temperature profiles separated in time, $T^{\mathrm{obs}}\left(z, t_{1}\right)$ and $T^{\mathrm{obs}}\left(z, t_{2}\right)$ :

$$
\begin{aligned}
& \frac{\partial T(z, t)}{\partial t}= \\
& \frac{\partial}{\partial z}\left(\kappa(z, t) \frac{\partial T(z, t)}{\partial z}\right)-w(z, t) \frac{\partial T(z, t)}{\partial z}+\frac{1}{\rho C_{p}} \frac{\partial I(z)}{\partial z}
\end{aligned}
$$

Here $\rho$ is density, $C_{p}$ is the specific heat and $I(z)$ is the shortwave radiation flux, using a surface shortwave flux of $274 \mathrm{~W} \mathrm{~m}^{-2}$ minus an albedo of $4 \%$, computed from shipboard data, and the attenuation model of Paulson and Simpson (1977) for Type I water. The non-solar surface heat flux was computed as the difference between the heat gain $T^{\mathrm{obs}}(z$, $\left.t_{2}\right)-T^{\mathrm{obs}}\left(z, t_{1}\right)$, the surface shortwave flux, and the advective and diffusive heat fluxes computed from the current iteration values of $w$ and $\kappa$ at $150 \mathrm{~m}$. The bottom boundary condition was prescribed as changing linearly in time from $T^{\mathrm{obs}}\left(150 \mathrm{~m}, t_{1}\right)$ to $T^{\mathrm{obs}}\left(150 \mathrm{~m}, t_{2}\right)$. The values of $\kappa(z, t)$ and $w(z, t)$ were optimized to temperature data under 3 possible cases: no advection $(w=0)$ and $\kappa$ optimized (Case 1); both $w$ and $\kappa$ optimized (Case 2); and $w$ optimized and $\kappa$ set to the canonical estimate of $10^{-5} \mathrm{~m}^{2} \mathrm{~s}^{-1}$ (Large et al., 1994; Polzin et al., 1995) (Case 3). These 3 cases cover the range of possible combinations (no-advection high-diffusion through highadvection low-diffusion).

The depth-dependence of $w$ was parameterized based on 3-D physical simulations of eddy $\mathrm{C} 1$ (Ledwell et al., 2008), which indicated downwelling at eddy center with an extremum at the mixed-layer depth $\left(z_{\mathrm{mld}}\right)$ and suggested the following piecewise-linear form above $150 \mathrm{~m}$ :

$$
\begin{aligned}
& w(z, t)=w_{\max } z / z_{\mathrm{mld}}(t) \quad \text { for } 0>z>z_{\mathrm{mld}}(t) \\
& w(z, t)=w_{\mathrm{max}}+w_{\mathrm{grad}}\left(z-z_{\mathrm{mld}}(t)\right) \\
& \text { for } z_{\mathrm{mld}}(t)>z>-150 \mathrm{~m}
\end{aligned}
$$


Table 2. Model results. $\kappa_{\text {deep }}$ is the vertical diffusion coefficient, $w_{\max }$ and $w_{\text {grad }}$ are vertical velocity parameters, NCP is net community production of oxygen, STD is standard deviation. $\mathrm{d}\left[\mathrm{O}_{2}\right] / \mathrm{dt}$, NCP and all subsequent oxygen fluxes are in $\mathrm{mmol} \mathrm{O}_{2} \mathrm{~m}^{-2} \mathrm{~d}^{-1}$. The air-sea $\mathrm{O}_{2}$ flux is defined negative upward while the diffusive and advective $\mathrm{O}_{2}$ fluxes at $100 \mathrm{~m}$ are defined negative downward, i.e. negative indicates a loss to the $0-100 \mathrm{~m} \mathrm{O}_{2}$ integral. STD is computed as the square root of the sum of the error variances from various sources (see Sect. 3.4).

\begin{tabular}{|c|c|c|c|c|c|c|c|c|c|c|c|c|}
\hline \multirow[b]{2}{*}{ Variable (units) } & \multicolumn{4}{|c|}{21 June-1 July } & \multicolumn{4}{|c|}{1 July-27 July } & \multicolumn{4}{|c|}{27 July-3 August } \\
\hline & Case 1 & Case 2 & Case 3 & Mean $( \pm$ STD $)$ & Case 1 & Case 2 & Case 3 & Mean ( \pm STD $)$ & Case 1 & Case 2 & Case 3 & Mean $( \pm$ STD $)$ \\
\hline$\kappa_{\text {deep }}\left(\mathrm{m}^{2} \mathrm{~s}^{-1}\right)$ & $3.1 \times 10^{-4}$ & $4.0 \times 10^{-5}$ & $1.0 \times 10^{-5}$ & & $2.7 \times 10^{-4}$ & $4.8 \times 10^{-5}$ & $1.0 \times 10^{-5}$ & & $3.2 \times 10^{-4}$ & $1.21 \times 10^{-4}$ & $1.0 \times 10^{-5}$ & \\
\hline$w_{\max }\left(\mathrm{m} \mathrm{day}^{-1}\right)$ & 0 & -0.53 & -0.57 & & 0 & -0.46 & -0.51 & & 0 & -0.38 & -0.54 & \\
\hline$w_{\text {grad }}\left(\right.$ day $\left.^{-1}\right)$ & 0 & 0 & 0 & & 0 & $-3.5 \times 10^{-5}$ & 0 & & 0 & 0 & 0 & \\
\hline $\mathrm{d}\left[\mathrm{O}_{2}\right] / \mathrm{dt}, 0-100 \mathrm{~m}$ & 0.6 & 0.6 & 0.6 & & -17.1 & -17.1 & -17.1 & & -14.9 & -14.9 & -14.9 & \\
\hline NCP, $0-100 \mathrm{~m}$ & 21.0 & 17.8 & 17.5 & $19( \pm 6)$ & -1.9 & -2.2 & -4.0 & $-3( \pm 7)$ & 15.9 & 10.5 & 5.5 & $11( \pm 8)$ \\
\hline Air-sea $\mathrm{O}_{2}$ flux & -9.2 & -10.4 & -10.9 & $-10( \pm 4)$ & -4.6 & -5.3 & -4.0 & $-5( \pm 7)$ & -11.6 & -11.3 & -10.9 & $-11( \pm 7)$ \\
\hline Diffusive flux at $100 \mathrm{~m}$ & -11.1 & -1.4 & -0.4 & & -10.6 & -1.9 & -0.4 & & -19.4 & -7.7 & -0.7 & \\
\hline Advective flux at $100 \mathrm{~m}$ & 0 & -118.5 & -127.4 & & 0 & -101.5 & -113.4 & & 0 & -84.9 & -120.3 & \\
\hline Horizontal advection & 0 & 113.1 & 121.8 & & 0 & 93.9 & 104.7 & & 0 & 78.5 & 111.4 & \\
\hline Advection + diffusion & -11.1 & -6.7 & -5.9 & $-8( \pm 2)$ & -10.6 & -9.5 & -9.1 & $-10( \pm 2)$ & -19.4 & -14.1 & -9.5 & $-14( \pm 5)$ \\
\hline
\end{tabular}

For Case $1 w_{\max }$ and $w_{\operatorname{grad}}$ are both set to zero. For Cases 2 and $3, w_{\max }$ and $w_{\text {grad }}$ are optimized (see Table 2) with the constraint $w_{\text {grad }} \leq 0$. Note that a depth-dependent $w$ requires horizontal convergence or divergence for mass conservation. Thus horizontal advective fluxes of temperature (and oxygen) are included in the model, assuming no horizontal gradients in $T$ or $\mathrm{O}_{2}$. This is accomplished numerically implicitly by evaluating $w \partial T / \partial z$ at grid box interfaces.

Three different $\kappa(z, t)$ parameterizations were tried. A complex vertical mixing and mixed-layer model was not used because (a) it was thought best to optimize $\kappa$ to the temperature data, (b) matching the observed $z_{\mathrm{mld}}\left(t_{2}\right)$ exactly is critical to optimizing both the $\mathrm{T}$ and $\mathrm{O}_{2}$ models, (c) diurnal $z_{\mathrm{mld}}$ cycles introduce the issue of phase errors in the optimization, (d) the observed mixed-layer depth was relatively constant, (e) lack of surface forcing data between cruises, and (f) at eddy center the horizontal velocities are zero (except in the Ekman layer), such that $\kappa$ formulas that rely on vertical shear in horizontal velocity are not wellsuited. All three parameterizations used a constant $\kappa_{\text {mld }}$ of $5 \times 10^{-3} \mathrm{~m}^{2} \mathrm{~s}^{-1}$ (Pacanowski and Philander, 1981) above $z_{\mathrm{mld}}(t)$. The mixed-layer depth was prescribed to change linearly with time between observed values. Below $z_{\mathrm{mld}}(t)$, the first parameterization tried was $\kappa(z, t)=\alpha / N(z, t)$, where $N$ is the Brunt-Vaisala frequency and $\alpha$ an optimized constant (Gargett, 1984). This parameterization was incapable of fitting the temperature data well, as it resulted in too little diffusion just below the MLD (where $N$ is largest) and too much diffusion at $150 \mathrm{~m}$ (where $N$ is smallest). Based on this finding, the opposite depth-dependence was tried with $\kappa(z)$ decreasing exponentially with depth below the MLD from a $\kappa_{\text {mld }}$ value to a background $\kappa_{\text {deep }}$ value, as suggested by turbulent kinetic energy and dissipation rate estimates (Girton and Sanford, 2006; Greenan, 2008). Even with the e-folding scale optimized, this formula did not fit the temperature data well either, as it prescribed too much mixing just below the mixed layer (where stratification is observed to be strongest). The third parameterization tried was simply a constant $\kappa_{\text {deep }}$ below $z_{\mathrm{mld}}(t)$. This formula was able to fit the temperature data adequately (Fig. 2a). This lack of correlation (or anticorrelation) between $\kappa_{\text {deep }}$ and $N$ is supported by fine-structure measurements (Gregg, 1989; Polzin et al., 1995). This is the parameterization used in the results presented. The $\kappa_{\text {deep }}$ value was optimized in Cases 1 and 2 and fixed in Case 3.

The 1-D temperature model was initialized with $T^{\mathrm{obs}}(z$, $t_{1}$ ), run forward in time until $t_{2}$, and a Cost computed by comparing with $T^{\mathrm{obs}}\left(z, t_{2}\right)$. The parameters $w_{\max }, w_{\text {grad }}$ or $\kappa_{\text {deep }}$ were then perturbed, a new simulation conducted, and Costs compared, until optimal parameter values were obtained. These optimized parameter values were then used in the oxygen model.

A 1-D salinity model was also constructed, similar to the temperature model without the solar heating term, to obtain independent optimal estimates of $w_{\max }, w_{\text {grad }}$ and $\kappa_{\text {deep }}$. These estimates were generally 3 times greater than those obtained from the temperature model, rather than lower (Gargett, 2003), with $w$ several times higher than the 3-D model estimates (Ledwell et al., 2008) and $\kappa$ higher than even saltfinger estimates (Schmitt et al., 2005). Therefore the salinitybased estimates seemed less plausible. There are a few reasons why the salinity-based estimates may be less accurate. First, the salinity data exhibited significant small-scale variability within and just below the mixed layer, apparently the result of precipitation events, for which we do not have an adequate time series to use for the surface boundary condition. Second, in our dataset the vertical salinity gradient is small (relative to horizontal salinity gradients), such that the optimization of $w$ and $\kappa$ by salinity data should be less welldetermined than by temperature data. Thirdly, because of the weak vertical salinity gradient, the salinity data exhibited greater sensitivity to horizontal intrusions (Fig. 1). Consequently the (lower) temperature-optimized values of $w_{\max }$, $w_{\text {grad }}$ and $\kappa_{\text {deep }}$ were used for the oxygen model. 

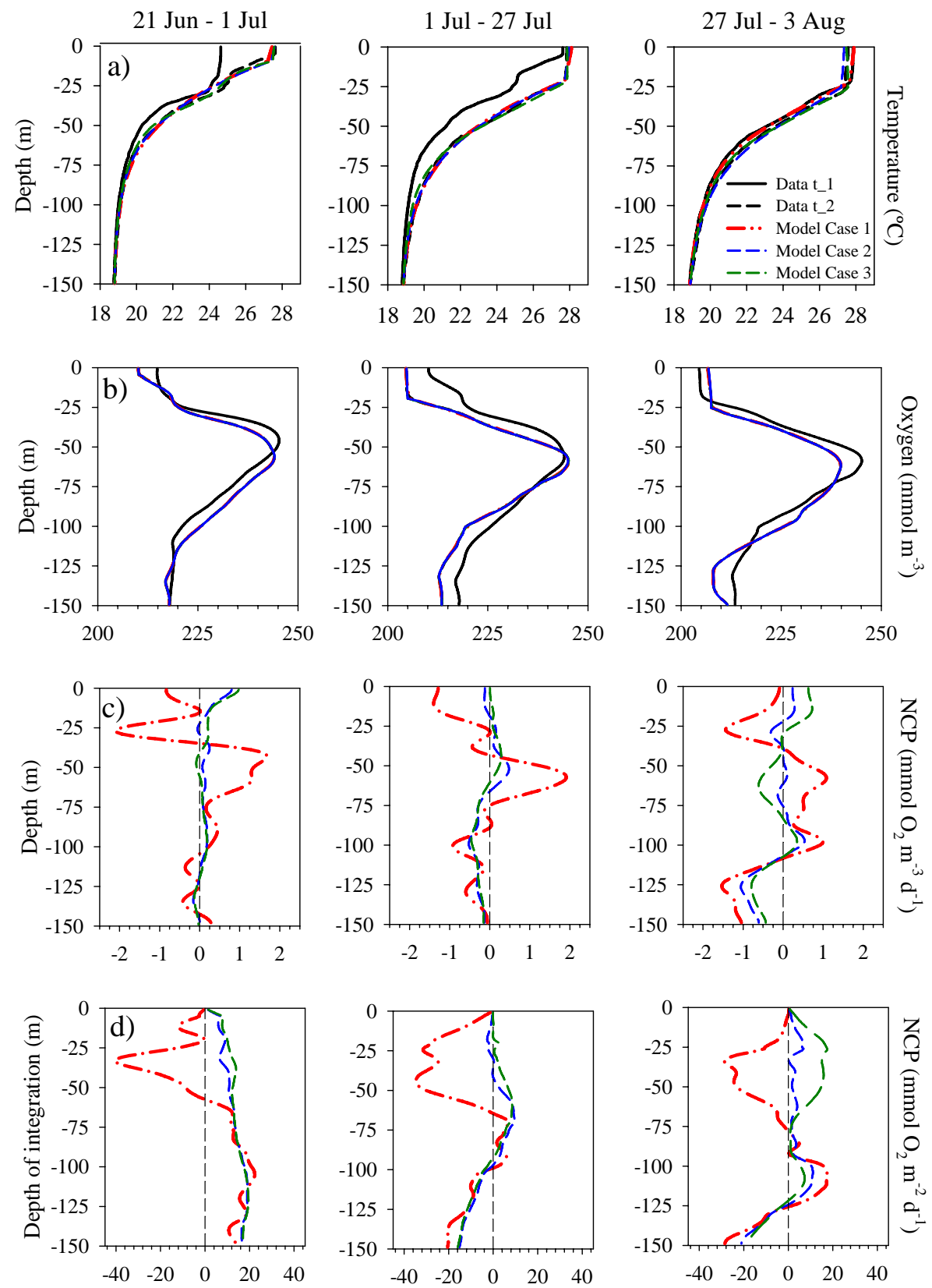

Fig. 2. Vertical distribution of temperature (a), oxygen (b), net community production (c) and depth-integrated net community production (d) at the center of cyclonic eddy $\mathrm{C} 1$ computed from the model runs Case 1 (red dot-dashed line), Case 2 (blue dashed line) and Case 3 (green dashed line), and for the initial $\left(t_{1}\right)$ and final $\left(t_{2}\right)$ in situ profiles of temperature (a) and oxygen (b). See Table 1 for details.

\subsubsection{Oxygen model}

The time-mean depth-dependent NCP rate $J(z)$ was estimated by data assimilation from two observed vertical $\mathrm{O}_{2}$ profiles separated in time, $\mathrm{O}_{2}^{\mathrm{obs}}\left(z, t_{1}\right)$ and $\mathrm{O}_{2}^{\mathrm{obs}}\left(z, t_{2}\right)$, using the following 1-D model:

$$
\frac{\partial \mathrm{O}_{2}(z, t)}{\partial t}=
$$

$$
\frac{\partial}{\partial z}\left(\kappa(z, t) \frac{\partial \mathrm{O}_{2}(z, t)}{\partial z}\right)-w(z, t) \frac{\partial \mathrm{O}_{2}(z, t)}{\partial z}+J(z)
$$


The diffusivity $\kappa(z, t)$ and the vertical velocity $w(z, t)$ were determined by optimization to temperature profile data, as discussed above. The bottom boundary condition was that $\mathrm{O}_{2}$ changed linearly in time from $\mathrm{O}_{2}^{\mathrm{obs}}\left(150 \mathrm{~m}, t_{1}\right)$ to $\mathrm{O}_{2}^{\text {obs }}\left(150 \mathrm{~m}, t_{2}\right)$. At the sea surface, air-sea gas exchange was modeled as a diffusive flux following Wanninkhof (1992), Keeling et al. (1998), and Najjar et al. (2007), plus the two-part bubble flux term $\left(F_{\text {bub }}\right)$ of Stanley et al. (Stanley et al., 2006; Stanley et al., 2009):

$\mathrm{O}_{2}$ Flux $=k\left(\mathrm{O}_{2}-\left(p / p_{o}\right) \mathrm{O}_{2}^{\text {sat }}\right)-F_{\text {bub }}$

$k=0.31 U^{2} \sqrt{660 / S c}$

$S c=1638-81.83 T+1.483 T^{2}-0.008004 T^{3}$

$k$ is the gas transfer velocity in $\mathrm{cm} \mathrm{hr}^{-1}, p$ is atmospheric pressure, $\mathrm{O}_{2}^{\text {sat }}$ is the oxygen saturation value at standard pressure $p_{o}, U$ is wind speed in $\mathrm{m} \mathrm{s}^{-1}$, and $S c$ is the Schmidt number. For $\mathrm{O}_{2}^{\text {sat }}$, the formula of Garcia and Gordon (1992) was used, with surface temperature and salinity linearly interpolated in time from initial and final observed values, and $0.1^{\circ} \mathrm{C}$ subtracted to account for the cooler skin temperature (Emerson et al., 2008). $U$ was determined from 12-hourly QuikScat data, and $p$ from the 3-hourly NCEP NARR-A reanalysis, both of which agreed well with shipboard data. The Stanley et al. $F_{\text {bub }}$ formula also requires air temperature and relative humidity (to compute dry atmosphere pressure and hence partial pressure of atmospheric oxygen), which were also taken from the NCEP NARR-A reanalysis. For comparison, the simpler bubble flux parameterization of Woolf and Thorpe (1991) was also tried:

$F_{\text {bub }}=0.01\left(U / U_{0}\right)^{2} k\left(p / p_{o}\right) \mathrm{O}_{2}^{\text {sat }}$

where $U_{0}$ is $9 \mathrm{~m} \mathrm{~s}^{-1}$, an empirical constant calibrated specifically for oxygen. However the more rigorous Stanley formula is used in the cases presented in Table 2.

An initial guess for the biological term $J(z)$ was made as $\left(\mathrm{O}_{2}^{\text {obs }}\left(z, t_{2}\right)-\mathrm{O}_{2}^{\text {obs }}\left(z, t_{1}\right)\right) /\left(t_{2}-t_{1}\right)$. The 1-D model was then initialized with $\mathrm{O}_{2}^{\text {obs }}\left(z, t_{1}\right)$, run forward in time until $t_{2}$, and the mean squared misfit computed as:

Cost $=\left(\frac{1}{150 \mathrm{~m}} \int_{0}^{150 \mathrm{~m}}\left(\mathrm{O}_{2}^{\mathrm{obs}}\left(z, t_{2}\right)-\mathrm{O}_{2}\left(z, t_{2}\right)\right)^{2} \partial z\right)^{0.5}$

If Cost was less than $0.002 \mu \mathrm{mol} \mathrm{O}_{2} \mathrm{~kg}^{-1}$ from the previous estimate of Cost, the computation was ended. Otherwise, $J(z)$ was "corrected" as:

$$
J^{\text {new }}(z)=J(z)+0.75\left(\mathrm{O}_{2}^{\text {obs }}\left(z, t_{2}\right)-\mathrm{O}_{2}\left(z, t_{2}\right)\right) /\left(t_{2}-t_{1}\right) .
$$

Biogeosciences, 6, 1799-1810, 2009
A new run was then conducted. The fraction of 0.75 is used for gradual convergence. In this way $J(z)$ was optimized so that $\mathrm{O}_{2}\left(z, t_{2}\right)$ fit $\mathrm{O}_{2}^{\mathrm{obs}}\left(z, t_{2}\right)$.

\section{Results and discussion}

\subsection{In situ observations}

Vertical profiles at the center of eddy $\mathrm{C} 1$ show the temporal evolution in properties between late June and early August 2004 (Fig. 1). Isotherms and isohalines deepened from 21 June to 3-4 August, although cooling of the upper $30 \mathrm{~m}$ appeared between 27-28 July and 3-4 August. In agreement with the temporal evolution of the thermohaline properties, the oxygen maximum also deepened from 21-22 June to 3-4 August. Surface oxygen decreased as temperature rose from 21-22 Jun to 27-28 July, always staying a few percent above oxygen saturation. The nitracline and deep chlorophyll maximum were located at about $100 \mathrm{~m}$. Nitrate and chlorophyll appeared to deepen from 21-22 June to 27-28 July and then shoal from 27-28 July to 3-4 August, but because of the coarse vertical resolution of the nitrate and chlorophyll data, and the observed small-scale horizontal or temporal variability in nitrate and chlorophyll data on 27-28 July (Fig. 1), we are not completely confident in their apparent temporal evolution. High spatial resolution data from the Video Plankton Recorder towed across $\mathrm{C} 1$ showed the chlorophyll distribution to be patchy in the vicinity of eddy center (McGillicuddy et al., 2007).

The vertical distributions of in vitro NCP, R, and GPP rates at center of $\mathrm{C} 1$ at the beginning (22 June) and the end (5 August) of the sampling period are shown in Fig. 3. On 22 June NCP rates were positive in the upper $40 \mathrm{dbar}$ and decreased to almost zero further down. Maximum values of $\mathrm{NCP}$ were found at the surface $\left(0.35 \pm 0.05 \mathrm{mmol} \mathrm{O}_{2} \mathrm{~m}^{-3}\right.$ $\mathrm{d}^{-1}$ ). Dramatic changes between late June and early August were observed in the upper $40 \mathrm{dbar}$, where a decrease to negative values $\left(-0.5 \mathrm{mmol} \mathrm{O}_{2} \mathrm{~m}^{-3} \mathrm{~d}^{-1}\right)$ was observed in NCP rates. Depth-integrated rates showed a shift from net autotrophy $\left(7 \pm 3 \mathrm{mmol} \mathrm{O}_{2} \mathrm{~m}^{-2} \mathrm{~d}^{-1}\right)$ to net heterotrophy $\left(-25 \pm 5 \mathrm{mmol} \mathrm{O}_{2} \mathrm{~m}^{-2} \mathrm{~d}^{-1}\right)$ in the metabolic balance of the photic layer. Respiration rates on 5 August $(58 \pm 8 \mathrm{mmol}$ $\mathrm{O}_{2} \mathrm{~m}^{-2} \mathrm{~d}^{-1}$ ) were more than double the rates estimated on 22 June $\left(22 \pm 7 \mathrm{mmol} \mathrm{O}_{2} \mathrm{~m}^{-2} \mathrm{~d}^{-1}\right)$.

The sea level anomaly associated with eddy $\mathrm{C} 1$ decreased by half from late June to early August (Mourino-Carballido and McGillicuddy, 2006). Small changes were observed in phytoplankton community composition through the sampling period. This was typically dominated by prymnesiophytes, cyanobacteria and Prochlorococcus groups in late June (Nardello and McGillicuddy, 2006). In early August the Prochlorococcus contribution grew by $7 \%$, at the expense of prymnesiophytes. Primary production rates estimated from the ${ }^{14} \mathrm{C}$ incorporation technique $\left({ }^{14} \mathrm{C} \mathrm{PP}\right)$ did not change 

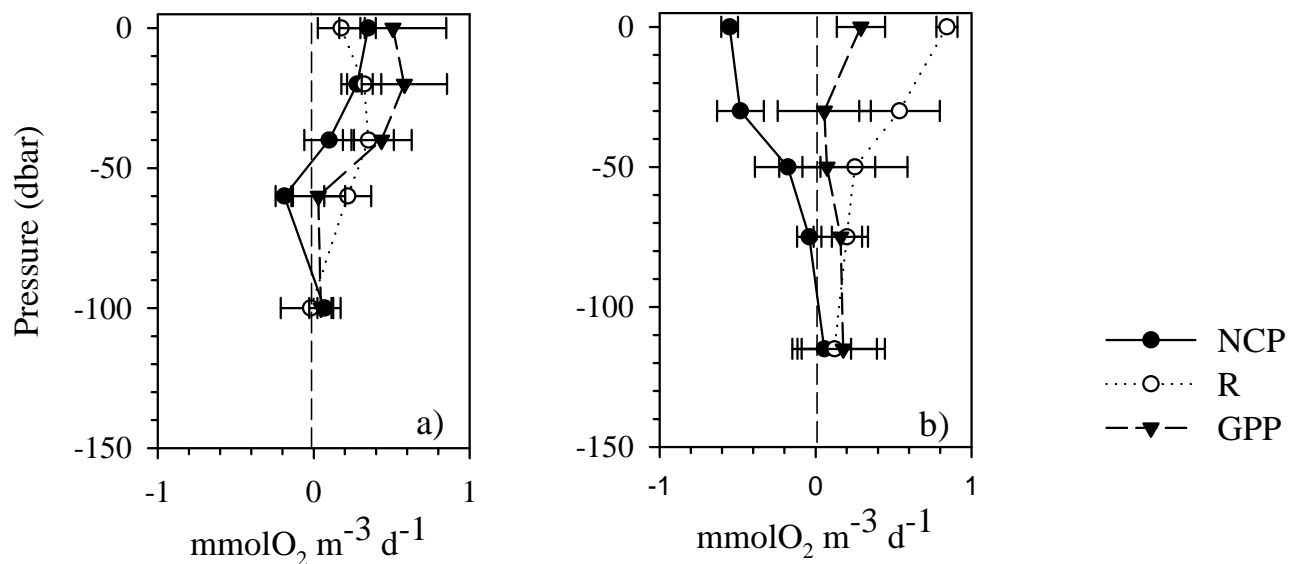

Fig. 3. Profiles of net community production (NCP), respiration (R), and gross primary production (GPP) rates at the center of cyclonic eddy C1 on (a) 22 June (OC404-1 st 20) and (b) 5 August (OC404-4 st 50).

significantly from the beginning to the end of the sampling period (Ewart et al., 2008). No important changes in bacterial biomass or bacterial production were observed between cruises (Ewart et al., 2008). Particle export fluxes calculated from ${ }^{234} \mathrm{Th}$ method showed a decrease in the magnitude of carbon fluxes (Buesseler et al., 2008).

Note that comparison of the in vitro $\mathrm{NCP}$ and the ${ }^{14} \mathrm{C}$ PP measurements is not straightforward. NCP estimates gross primary production minus community respiration over $24 \mathrm{~h}$, whereas dawn-to-dusk ${ }^{14} \mathrm{C}$ PP measures gross primary production minus autotrophic respiration (Marra, 2002). Since the two types of measurements available in this study are few and they were not made at the same times or locations, a precise intercomparison of both techniques can not be resolved with this dataset. Although we can not discard the possibility that part of the changes observed in $\mathrm{C} 1$ were associated with imperfect sampling of submesoscale or day-to-day variability, most evidence suggests that during the sampling period the eddy was in a state of declining biological response. This is consistent with the reduction in NCP measured in the photic layer of $\mathrm{C} 1$ by the in vitro technique.

\subsection{Temperature model results}

The observed deepening of the isotherms can be successfully modeled either by strong vertical diffusion, downwelling or a combination (Fig. 2a). For diffusion alone to explain the deepening, vertical diffusivities of $2.7-3.2 \times 10^{-4} \mathrm{~m}^{2} \mathrm{~s}^{-1}$ are required (Case 1 in Table 2). These values are an order of magnitude larger than estimates made near $90 \mathrm{~m}$ in an eddy investigated in the Sargasso Sea in summer 2005 (Ledwell et al., 2008), but may be reasonable values just below the mixed layer (Girton and Sanford, 2006). For downwelling alone to explain the deepening, rates of $0.5-0.6 \mathrm{~m} \mathrm{~d}^{-1}$ are needed (Case 3 in Table 2), which is twice that estimated in idealized 3-D simulations but similar to rates measured from a $\mathrm{SF}_{6}$ tracer release in the 2005 anticyclone (Ledwell et al.,
2008). Downwelling at the center of a cyclone is consistent with the expected wind-eddy interaction and is supported by the observed decline in sea level anomaly. Case 2 optimizes to significant downwelling with enhanced diffusivities similar to that observed in $2005\left(3.5 \times 10^{-5} \mathrm{~m}^{2} \mathrm{~s}^{-1}\right.$; Ledwell et al., 2008). It is encouraging that all three time periods give similar optimized values for $\kappa$ and $w$, despite the very different temperature evolutions (Fig. 2a). The model NCP estimates are not sensitive to whether the isopycnal deepening is caused by advection or diffusion (Table 2).

\subsection{Oxygen model results}

Model NCP is optimized to fit the final oxygen profiles accurately (Fig. 2b). The model NCP profiles show significant vertical variability between cases and periods (Fig. 2c), suggesting the vertical structure of NCP is not well constrained. The diffusion-dominated Case 1 places most of the NCP at the oxygen maximum, while the downwelling-dominated Cases 2 and 3 generally place most of the NCP in the mixed layer. The NCP profiles also contain 10-m scale vertical variability, due to subtle differences between initial and final oxygen profiles likely associated with internal wave displacements. Periods 1 (21 June-1 July) and 3 (27 July-3 August) estimate some net oxygen production near the nitracline (ca. $100 \mathrm{~m}$ ), related to nitrate-based new production, while Period 2 (1-27 July) does not. Yet in all periods and cases the NCP occurs primarily far above the nitracline, indicating either new production by nitrogen fixation or atmospheric deposition, or autotrophic and heterotrophic processes using different stoichiometric ratios. Consequently Redfield oxygen-tonitrogen conversions in these NCP estimates may not be appropriate. These results are in agreement with observations of nitrate uptake and carbon fixation across the photic layer of the subtropics (Painter et al., 2007).

Figure $2 d$ shows the sensitivity of vertically-integrated NCP to the depth of integration. In Periods 1 and 3 the 
highest values are obtained near $100 \mathrm{~m}$, below which the integrals decrease due to remineralization. However in Period 2 values decline below $70 \mathrm{~m}$. The vertically-integrated $(0-100 \mathrm{~m})$ model NCP rates estimate a net autotrophy of $19 \pm 6 \mathrm{O}_{2} \mathrm{~m}^{-2} \mathrm{~d}^{-1}$ in the first period decreasing to $-3 \pm 7$ and $11 \pm 8 \mathrm{mmol} \mathrm{O}_{2} \mathrm{~m}^{-2} \mathrm{~d}^{-1}$ in the second and third periods, respectively (Table 2), with an average of $4 \pm 6 \mathrm{mmol}$ $\mathrm{O}_{2} \mathrm{~m}^{-2} \mathrm{~d}^{-1}$ over these 43 days. The model concludes that the top $100 \mathrm{~m}$ is net autotrophic or balanced because, even though the $0-100 \mathrm{~m}$ oxygen inventory is generally decreasing, the sums of the outward fluxes at $100 \mathrm{~m}$ and $0 \mathrm{~m}$ are greater (Table 2). The downward flux at $100 \mathrm{~m}$, whether due to downwelling or downgradient diffusion, is consistently estimated at $8-14 \mathrm{mmol} \mathrm{O} \mathrm{m}^{-2} \mathrm{~d}^{-1}$ (Table 2), constrained by the temperature evolution. The net sea-to-air oxygen flux is also consistently estimated as upward at $5-11 \mathrm{mmol}$ $\mathrm{O}_{2} \mathrm{~m}^{-2} \mathrm{~d}^{-1}$, due to the $2.1 \pm 0.6 \%$ supersaturation of surface waters, despite the downward bubble flux. The mean air-sea flux in this eddy $\left(3 \pm 2 \mathrm{~mol} \mathrm{O}_{2} \mathrm{~m}^{-2} \mathrm{yr}^{-1}\right)$ is less than previous climatological estimates for July near Bermuda (6-7 mol $\mathrm{O}_{2} \mathrm{~m}^{-2} \mathrm{yr}^{-1}$, Musgrave et al. (1988); $6.8 \mathrm{~mol} \mathrm{O}_{2} \mathrm{~m}^{-2} \mathrm{yr}^{-1}$ at $30.9 \mathrm{~N} 64.7 \mathrm{~W}$, Garcia and Keeling (2001)). The 1-D model suggests that both physical and biological processes contribute significantly to the oxygen inventory above $100 \mathrm{~m}$ in late summer, and that the observed changes in oxygen concentration are a residual between the two.

It is felt that Cases 2 and 3 are closest to the truth. The temperature model computed the 43-day non-solar surface heat flux as $39,-150$ and $-178 \mathrm{~W} \mathrm{~m}^{-2}$ for Cases 1,2 and 3 respectively, which the NCEP NARR-A atmospheric model estimated independently as $-182 \mathrm{~W} \mathrm{~m}^{-2}$. Thus the heat balance indicates Case 1 as unlikely, but Cases 2 and 3 as plausible. Regarding the oxygen model results, Cases 2 and 3 generally place maximum NCP in the mixed layer (Fig. 2c), which is more consistent with the in vitro experiments (Fig. 3) and profiles of ${ }^{14} \mathrm{C}$ assimilation at BATS (Steinberg et al., 2001). Case 1 places maximum NCP at the oxygen maximum near $50 \mathrm{~m}$, which makes less sense as this depth has neither enhanced nutrients nor highest light intensity. Case 1 also requires net heterotrophy at $30 \mathrm{~m}$, because high diffusion cannot explain the observed deepening of the oxygen maximum (Fig. 2b).

\subsection{Oxygen model sensitivity tests}

The oxygen model infers the NCP from the temporal change in oxygen concentration, the air-sea flux and the net advective-diffusive input. Here we examine the uncertainty in each of these estimates. In addition to providing our error estimates, this shows where improvement is most needed for making NCP estimates with this model.

The impact of the uncertainty in the initial and final mean temperature and oxygen profiles was estimated by trying different station combinations to compute the mean profiles (e.g. station 18 versus station 20 as the initial pro- file on 21 June), re-running both the temperature and oxygen models with the new profiles for Case 2, and computing the standard deviation of the resulting NCP estimates. The estimated $0-100 \mathrm{~m}$ NCP uncertainties are $\pm 4.4,3.3$ and $3.1 \mathrm{mmol} \mathrm{O}_{2} \mathrm{~m}^{-2} \mathrm{~d}^{-1}$ for periods 1,2 and 3, respectively. Thus sensitivity to our ability to accurately estimate the initial and final conditions (based on the variability of the observed profiles) is significant. The sensitivity of the air-sea flux and the advection+diffusion estimates to the mean profiles was smaller, averaging $\pm 1 \mathrm{mmol} \mathrm{O}_{2} \mathrm{~m}^{-2} \mathrm{~d}^{-1}$.

The air-sea flux estimate relies on several factors, the first being the $\mathrm{O}_{2}$ data calibration. The air-sea diffusive flux is driven by the supersaturation, and as this is only a few percent, a small calibration error can have a large impact. According to the BATS Methods handbook (Knap et al., 1993), field precision of bottle samples using the Winkler method versus CTD profiles can vary from 0.005 to $0.03 \mathrm{ml} \mathrm{L}^{-1}$. We will consider here a possible systematic calibration error of $1 \mathrm{mmol} \mathrm{O}_{2} \mathrm{~m}^{-3}$ added to (or subtracted from) all profiles. This causes a mean uncertainty in the air-sea flux of $\pm 3.6 \mathrm{mmol} \mathrm{O}_{2} \mathrm{~m}^{-2} \mathrm{~d}^{-1}$, which propagates directly into the NCP estimates, though the impact on the advection+diffusion term is negligible.

Another source of uncertainty in the air-sea flux is the equation used for the gas transfer velocity. To test sensitivity, the gas transfer velocity of Wanninkhof (1992) was increased and decreased by $25 \%$ in Case 2, spanning the formulas of Ho et al. (2006) and Nightingale et al. (2000). The Wanninkhof and McGillis (1999) formula is not considered as it includes the bubble flux within it, though for a case unlike here in which the bubble flux and diffusive flux were in the same direction. The $25 \%$ uncertainty changes the average air-sea flux by $\pm 3.2 \mathrm{mmol} \mathrm{O}_{2} \mathrm{~m}^{-2} \mathrm{~d}^{-1}$, which again propagates directly into the NCP uncertainty, with negligible impact on the advection+diffusion term.

Sensitivity to the bubble flux formula was examined for all Cases in all 3 periods. The Stanley et al. formula yielded a 43-day mean downward bubble flux of $9.8 \mathrm{mmol}$ $\mathrm{O}_{2} \mathrm{~m}^{-2} \mathrm{~d}^{-1}$ while the Woolf and Thorpe formula yielded $8.3 \mathrm{mmol} \mathrm{O} \mathrm{O}_{2} \mathrm{~m}^{-2} \mathrm{~d}^{-1}$. These are both close to the summer estimate at HOT of approximately $8 \mathrm{mmol} \mathrm{O}_{2} \mathrm{~m}^{-2} \mathrm{~d}^{-1}$ (Hamme and Emerson, 2006), and counterbalance more than half of the upward air-sea diffusive flux. This $1.5 \mathrm{mmol}$ $\mathrm{O}_{2} \mathrm{~m}^{-2} \mathrm{~d}^{-1}$ difference in the bubble flux estimate causes only a $0.8 \mathrm{mmol} \mathrm{O}_{2} \mathrm{~m}^{-2} \mathrm{~d}^{-1}$ difference in the net air-sea flux and the NCP, because the model requires oxygen concentrations to match the observed values.

Sensitivity to our linear MLD time series was estimated as follows. As a perturbation run, the MLD was fixed for the first $24 \mathrm{~h}$ to the initial observed MLD, and then it was changed abruptly to the final observed MLD for the remainder of the period. For the opposing perturbation, the MLD was fixed to the initial MLD until switching to the final MLD in the final $24 \mathrm{~h}$. While this perturbation method is crude, it likely encompasses one standard deviation of the variability. 
Note that the original profiles did not show great diurnal variability (Fig. 1). This yielded NCP error estimates of \pm 0.4 , 4.1 and $1.2 \mathrm{mmol} \mathrm{O}_{2} \mathrm{~m}^{-2} \mathrm{~d}^{-1}$ for periods 1,2 and 3 respectively, greatest for Period 2 because of its long duration and the large difference between the initial and final observed MLD. The uncertainty in the advection+diffusion term was on average $\pm 0.4 \mathrm{mmol} \mathrm{O}_{2} \mathrm{~m}^{-2} \mathrm{~d}^{-1}$.

Sensitivity to the uncertainty in the diffusivity and vertical velocities is illustrated in Table 2. While the uncertainty of any one of the vertical diffusion, vertical advection and horizontal advection terms is quite large, these estimates are not independent. Conservation of volume constrains that high horizontal advection can only exist with high vertical advection, and the observed temperature evolution constrains that vertical advection can only be high if vertical diffusion is low. These relationships cause their impacts on the oxygen budget to largely cancel. Consequently the variance in the net advection + diffusion term is much smaller than the variance in any individual term. The uncertainty in $\kappa$ versus $w$ causes an uncertainty in the net advection + diffusion term of \pm 2.3 , 0.6 and $4.0 \mathrm{mmol} \mathrm{O}_{2} \mathrm{~m}^{-2} \mathrm{~d}^{-1}$ for periods 1,2 and 3 respectively, with similar impact on NCP estimates, though only an average uncertainty of $\pm 0.4 \mathrm{mmol} \mathrm{O}_{2} \mathrm{~m}^{-2} \mathrm{~d}^{-1}$ on the air-sea fluxes.

Horizontal advection of $\mathrm{T}$ and $\mathrm{O}_{2}$ gradients (e.g. $u \partial \mathrm{O}_{2} / \partial x$ ) was neglected in the models, which is justifiable as follows. Eight of the nine runs in Table 2 have no horizontal divergence below the mixed-layer (i.e. $w_{\text {grad }}=0$ ). The remaining one has very weak divergence viz. if the downwelling occurs over a $20 \mathrm{~km}$ radius, the outward horizontal velocity below the mixed layer at radius $r=20 \mathrm{~km}$ is $-w_{\text {grad }} \pi r^{2} / 2 \pi r=4 \times 10^{-6} \mathrm{~m} \mathrm{~s}^{-1}$. More significant is the horizontal convergence that occurs in the mixed layer that feeds the downwelling. In the most extreme case (Period 1 Case 3) the inward horizontal velocity at $20 \mathrm{~km}$ radius is $w_{\max } \pi r^{2} / 2 \pi r z_{\text {mld }}=9.5 \times 10^{-3} \mathrm{~m} \mathrm{~s}^{-1}$. For the temperature model, any heat gain from $u \partial \mathrm{T} / \partial x$ in the mixed layer is already included in the non-solar surface heat flux, which is computed as the difference between the observed heat gain and the other fluxes. For oxygen, from CTD data and underway surface measurements $2 \mathrm{O}_{2} / \partial x$ in the mixed layer is estimated as $5 \times 10^{-5} \mathrm{mmol} \mathrm{O}_{2} \mathrm{~m}^{-4}$ (i.e. a concentration difference of $1 \mathrm{mmol} \mathrm{O}_{2} \mathrm{~m}^{-3}$ over $20 \mathrm{~km}$ ), such that $u \partial \mathrm{O}_{2} / \partial x$ vertically integrated over the mixed layer depth $\left(0.5 w_{\max } r \partial \mathrm{O}_{2} / \partial x\right)$ is $0.28 \mathrm{mmol} \mathrm{O}_{2} \mathrm{~m}^{-2} \mathrm{~d}^{-1}$ This is negligible compared to the estimates and uncertainties in Table 2 .

Another simplification in the temperature model was the use of a constant solar heat flux. Variations in the solar flux indicated by the shipboard and NCEP data were estimated, but were found to be a negligible source of error relative to the other sources.

The error estimates given in Table 2 are the square root of the sum of the squares of the uncertainties related to the initial and final profiles, $\mathrm{O}_{2}$ calibration, gas transfer velocity, bubble flux, mixed layer depth and the role of advection versus diffusion. The other error sources mentioned above were estimated as negligible in comparison. Although the error estimates are considerable, the model-derived in situ NCP estimates are statistically significantly greater than the in vitro NCP estimates.

\subsection{In vitro versus in situ geochemical derived rates of net production of oxygen}

Oxygen net production rates derived from the in vitro technique showed a shift from slight net autotrophy $\left(7 \pm 3 \mathrm{mmol} \mathrm{O}_{2} \mathrm{~m}^{-2} \mathrm{~d}^{-1}\right)$ to net heterotrophy $(-25 \pm 5 \mathrm{mmol}$ $\mathrm{O}_{2} \mathrm{~m}^{-2} \mathrm{~d}^{-1}$ ) at the center of eddy $\mathrm{C} 1$ from late June to early August. The in situ geochemical rates derived from the 1D model were higher than the in vitro NCP rates (19 to $-3 \mathrm{mmol} \mathrm{O}_{2} \mathrm{~m}^{-2} \mathrm{~d}^{-1}$ ) and reported net autotrophy or balance for the same period. The in situ rates also showed a decrease, although less intense, in NCP from the beginning to the end of the sampling period. This disagreement coincides with the comparison classically reported in the literature, with productivity inferred indirectly from in situ data being, in most cases, much greater than rates derived from the in vitro technique (Williams et al., 2004). The explanations proposed to explain this discrepancy include the different temporal and spatial scales involved in both types of measurements and potential methodological artefacts associated with the in vitro technique.

Karl et al. (2003) suggested that short intensive bursts of photosynthesis, which charge up the organic reservoir which is then slowly and steadily discharged by respiration, are regularly missed with traditional sampling techniques such as in vitro experiments. Juranek and Quay (2005) measured in vitro GPP and in situ GPP and NCP at Station ALOHA, in the North Pacific Subtropical Gyre, by using labeled and natural abundance isotopes of dissolved $\mathrm{O}_{2}$. According to these authors, the consistently higher in situ GPP, which integrates production over a $\sim 2$ week period, supports the argument that intermittency in primary production contributes substantially to long-term autotrophy. However, oxygen sensors deployed on profiling floats in the North and South Pacific subtropical gyres showed continuous oxygen increase below the mixed layer at a nearly constant rate, with episodic events not required to sustain positive oxygen production (Riser and Johnson, 2008). In our study, the in vitro and in situ estimates are made at the center of a single eddy, such that episodic pulses in photosynthesis associated with mesoscale variability cannot explain their discrepancy.

Our in vitro and in situ estimates also suggest some degree of temporal variability. Both techniques showed a decrease in NCP from the beginning to the end of the sampling period that is consistent with altimetric, hydrographic and biogeochemical data that suggest that during the sampling period eddy $\mathrm{C} 1$ was in a declining biological state (MourinoCarballido and McGillicuddy, 2006). However, we can not discard the possibility that the change in the in vitro estimates 
were, at least partially, due to submesoscale and/or day-today variability. Such variability might be expected from the observed submesoscale variability in the chlorophyll distribution (McGillicuddy et al., 2007), and daily variations in solar insolation.

A second, not exclusive, explanation would be related to methodological artefacts associated with the in vitro technique. Long incubations may lead to overestimations of community respiration as a result of an increase in the abundance (Pomeroy and Wiebe, 1993) and activity (Sherr et al., 1999) of heterotrophic bacteria and a reduction in the abundance and activity of picophytoplankton (Fernandez et al., 2003). An analysis of biomass and metabolism data of the main planktonic groups in the subtropical NE Atlantic showed the sum of all respiratory fluxes by the various microbial groups to be smaller than the mean community respiration derived from $\mathrm{O}_{2}$ in vitro technique (Maranon et al., 2007). That study indicated that bacterial respiration represented a maximum of $50 \%$ of community respiration only if a very low bacterial growth efficiency was used. The authors concluded that the paradigm that bacteria dominate carbon cycling in the unproductive ocean must be revised, or else that in vitro incubations misrepresent the real metabolic rates of one or several microbial groups. Bacterial respiration (ca. $233 \mathrm{mgC} \mathrm{m}^{-2} \mathrm{~d}^{-1}$ ) estimated from bacterial growth rates measured at cyclonic eddy $\mathrm{C} 1$ during 2004 summer cruises (Ewart et al., 2008), assuming the mean bacterial growth efficiency reported for the Sargasso Sea (ca. 0.13) (Carlson and Ducklow, 1996), explained only ca. 50\% of the dark respiration rate derived from in vitro changes in dissolved oxygen (ca. $545 \mathrm{mgC} \mathrm{m}^{-2} \mathrm{~d}^{-1}$ ). After comparing instantaneous rate measurements by $\mathrm{O}_{2}$ bottle incubations with a geochemical approach using continuous measurements of surface water $\mathrm{O}_{2} / \mathrm{Ar}$ ratios (Kaiser et al., 2005) during two Atlantic Meridional Transect cruises in 2005, Kaiser et al. (2006) concluded that bottle incubations are not suitable to correctly represent the net metabolic balance over larger temporal and spatial scales.

Previous studies have confirmed that (sub)mesoscale features contribute significantly to the variability observed in photosynthesis (Mourino-Carballido and McGillicuddy, 2006) and respiration processes (Mourino-Carballido, 2009). However, our results indicate that undersampling of mesoscale features is probably not the main reason for the traditional disagreement between in vitro and in situ techniques. Due to differences from temporal or submesoscale variability or methodological artefacts, our study reinforces the conclusion of Kaiser et al. (2006) that in situ geochemical techniques are more appropriate to describe the balance between photosynthesis and respiration over large temporal and spatial scales. Nevertheless, in vitro techniques constitute useful tools for studying processes occurring over relatively short temporal and spatial scales. Understanding the metabolic balance of the open ocean, and its variability over various temporal and spatial scales, is crucial to comprehend the net contribution of the marine biota to the global carbon cycle. The accomplishment of this important task requires effort in the direction of combining in vitro and in situ geochemical determinations of the balance between primary production and total respiration.

Acknowledgements. We are grateful to the participants of OC404-1 and OC404-4 cruises for their valuable support at sea. We thank J. Doutt and D. Nowack for the design and construction of the temperature control system used in summer 2004, R. Stanley for help implementing her bubble flux model, and E. Marañón and the anonymous reviewers for valuable comments on this manuscript. B. Mouriño-Carballido was supported by a Fulbright postdoctoral fellowship and the Isidro Parga Pondal program from the Galician government.

Edited by: J. Middelburg

\section{References}

Buesseler, K. O., Lamborg, C., Cai, P., Escoube, R., Johnson, R., Pike, S., Masque, P., McGillicuddy, D., and Verdeny, E.: Particle fluxes associated with mesoscale eddies in the Sargasso Sea, Deep-Sea Res. II, 55, 1426-1444, 2008.

Carlson, C. A. and Ducklow, H. W.: Growth of bacterioplankton and consumption of dissolved organic carbon in the Sargasso Sea, Aquat. Microb. Ecol., 10, 69-85, 1996.

Chipman, D. W., Marra, J., and Takahashi, T.: Primary production at $47^{\circ} \mathrm{N}$ and $20^{\circ} \mathrm{W}$ in the North Atlantic Ocean: A comparison between the ${ }^{14} \mathrm{C}$ incubation method and the mixed layer carbon budget, Deep Sea Res. II, 40, 151-169, 1993.

Duarte, C. M., Agusti, S., Aristegui, J., Gonzalez, N., and Anadon, R.: Evidence for a heterotrophic subtropical Northeast Atlantic, Limnol. Oceanogr., 46, 425-428, 2001.

Emerson, S., Stump, C., and Nicholson, D.: Net biological oxygen production in the ocean: Remote in situ measurements of $\mathrm{O}_{2}$ and $\mathrm{N}_{2}$ in surface waters, Global Biogeochem. Cy., 22, GB3023, doi:10.1029/2007GB003095, 2008.

Eppley, R. W. and Peterson, B. J.: Particulate organic-matter flux and planktonic new production in the deep ocean, Nature, 282, 677-680, 1979.

Ewart, C. S., Meyers, M. K., Wallner, E. R., McGillicuddy, D. J., and Carlson, C. A.: Microbial dynamics in cyclonic and anticyclonic mode-water eddies in the Northwestern Sargasso Sea, Deep-Sea Res. II, 55, 1334-1347, 2008.

Fernandez, E., Maranon, E., Moran, X. A. G., and Serret, P.: Potential causes for the unequal contribution of picophytoplankton to total biomass and productivity in oligotrophic waters, Mar. Ecol. Prog. Ser., 254, 101-109, 2003.

Garcia, H. E. and Gordon, L. I.: Oxygen solubility in seawater - better fitting equations, Limnol. Oceanogr., 37, 1307-1312, 1992.

Gargett, A. E.: Vertical eddy diffusivity in the ocean interior, J. Mar. Res., 42, 359-393, 1984.

Gargett, A. E.: Differential diffusion: An oceanographic primer, Progr. Oceanogr., 56, 559-570, 2003.

Girton, J. B. and Sanford, T. B.: EMAPEX observations in a modewater eddy: Internal waves, mean velocity structure and upperocean mixing, EOS Transactions 87(36 suppl.), abstract, AGU Ocean Sciences Meeting, Hawaii, USA, 2006. 
Greenan, B. J. W.: Shear and Richardson number in a mode-water eddy, Deep-Sea Res. II, 55, 1161-1178, 2008.

Gregg, M. C.: Scaling turbulent dissipation in the thermocline, J. Geophys. Res., 94, 9686-9698, 1989.

Hamme, R. C. and Emerson, S. R.: Constraining bubble dynamics and mixing with dissolved gases: Implications for productivity measurements by oxygen mass balance, J. Mar. Res., 64, 73-95, 2006.

Ho, D. T., Law, C. S., Smith, M. J., Schlosser, P., Harvey, M., and Hill, P.: Measurements of air-sea gas exchange at high wind speeds in the Southern Ocean: Implications for global parameterizations, Geophys. Res. Lett., 33, L16611, doi:10.1029/2006GL026817, 2006.

Juranek, L. W. and Quay, P. D.: In vitro and in situ gross primary and net community production in the North Pacific subtropical gyre using labeled and natural abundance isotopes of dissolved $\mathrm{O}_{2}$, Global Biogeochem. Cy., 19, GB3009, doi:3010.1029/2004GB002384, 2005 .

Kaiser, J., Reuer, M. K., Barnett, B., and Bender, M. L.: Marine productivity estimates from continuous $\mathrm{O}_{2} / \mathrm{Ar}$ ratio measurements by membrane inlet mass spectrometry, Geophys. Res. Lett., 32, L19605, doi:19610.11029/12005GL023459, 2005.

Kaiser, J., Gist, N., Bender, M., and Robinson, C.: The metabolic balance of the surface ocean along two Atlantic Meridional Transects, Geophys. Res. Abstracts, 8, 08599, 2006.,

Karl, D. M., Laws, E. A., Morris, P., Williams, P. J. 1., and Emerson, S.: Global carbon cycle - metabolic balance of the open sea, Nature, 426, 32, 2003.

Keeling, R. F., Stephens, B. B., Najjar, R. G., Doney, S. C., Archer, D., and Heimann, M.: Seasonal variations in the atmospheric $\mathrm{O}_{2} / \mathrm{N}_{2}$ ratio in relation to the kinetics of air-sea gas exchange, Global Biogeochem. Cy., 12, 141-163, 1998.

Keeling, R. F. and Garcia, H. E.: The change in oceanic $\mathrm{O}_{2}$ inventory associated with recent global warming, Proc. Natl. Acad. Sci. USA, 99, 7848-7853, 2002.

Knap, A. H., Michaels, A. F., Dow, R. L., Johnson, R. J., Gundersen, K., Sorensen, J. C., Close, A., Howse, F., Hammer, M., Bates, N. R., Doyle, A., and Waterhouse, T.: BATS methods manual, version 3. US JGOFS planning office, Woods Hole, MA, USA, 1993.

Large, W. G., McWilliams, J. C., and Doney, S. C.: Oceanic vertical mixing - a review and a model with a nonlocal boundary-layer parameterization, Rev. Geophys., 32, 363-403, 1994.

Ledwell, J. R., McGillicuddy, D. J., and Anderson, L. A.: Nutrient flux into an intense deep chlorophyll layer in a mode-water eddy, Deep-Sea Res. II, 55, 1139-1160, 2008.

Maixandeau, A., Lefevre, D., Karayanni, H., Christaki, U., Van Wambeke, F., Thyssen, M., Denis, M., Fernandez, C. I., Uitz, J., Leblanc, K., and Queguiner, B.: Microbial community production, respiration, and structure of the microbial food web of an ecosystem in the Northeastern Atlantic Ocean, J. Geophys. Res., 110, C07S17, doi:10.1029/2004JC002694, 2005.

Maranon, E., Perez, V., Fernandez, E., Anadon, R., Bode, A., Gonzalez, N., Huskin, I., Isla, A., Moran, X. A. G., Mourino, B., Quevedo, M., Robinson, C., Serret, P., Teiral, E., Varela, M. M., Woodward, E. M. S., and Zubkov, M. V.: Planktonic carbon budget in the Eastern subtropical North Atlantic, Aquat. Microb. Ecol., 48, 261-275, 2007.

Marra, J.: Approaches to the measurement of plankton production, in: Phytoplankton productivity: Carbon assimilation in marine and freshwater ecosystems, edited by: Williams, P. J. 1., Thomas, D. N., and Reynolds, C. S., Cambridge, Blackwells, 78-108, 2002.

McGillicuddy, D. J., Jr., Anderson, L. A., Bates, N. R., Bibby, T., Buesseler, K. O., Carlson, C. A., Davis, C. S., Ewart, C., Falkowski, P. G., Goldthwait, S. A., Hansell, D. A., Jenkins, W. J., Johnson, R., Kosnyrev, V. K., Ledwell, J. R., Li, Q. P., Siegel, D. A., and Steinberg, D. K.: Eddy/wind interactions stimulate extraordinary mid-ocean plankton blooms, Science, 316, 10211026, 10.1126/science.1136256, 2007.

Moran, X. A. G., Perez, V., and Fernandez, E.: Mismatch between community respiration and the contribution of heterotrophic bacteria in the NE Atlantic open ocean: What causes high respiration in oligotrophic waters?, J. Mar. Res., 65, 545-560, 2007.

Mourino-Carballido, B. and McGillicuddy, D. J.: Mesoscale variability in the metabolic balance of the Sargasso Sea, Limnol. Oceanogr., 51, 2675-2689, 2006.

Mourino-Carballido, B.: Eddy-driven pulses of respiration in the Sargasso Sea, Deep-Sea Res. I, 56, 1242-1250, 2009.

Musgrave, D. L., Chou, J., and Jenkins, W. J.: Application of a model of upper-ocean physics for studying seasonal cycles of oxygen, J. Geophys. Res., 93, 15679-15700, 1988.

Najjar, R. G., and Keeling, R. F.: Mean annual cycle of the air-sea oxygen flux: A global view, Global Biogeochem. Cy., 14, 573$584,2000$.

Najjar, R. G., Jin, X., Louanchi, F., Aumont, O., Caldeira, K., Doney, S. C., Dutay, J. C., Follows, M., Gruber, N., Joos, F., Lindsay, K., Maier-Reimer, E., Matear, R. J., Matsumoto, K., Monfray, P., Mouchet, A., Orr, J. C., Plattner, G. K., Sarmiento, J. L., Schlitzer, R., Slater, R. D., Weirig, M. F., Yamanaka, Y., and Yool, A.: Impact of circulation on export production, dissolved organic matter, and dissolved oxygen in the ocean: Results from phase II of the ocean carbon-cycle model intercomparison project (OCMIP-2), Global Biogeochem. Cy., 21, GB3007, doi:10.1029/2006GB002857, 2007.

Nardello, I., and McGillicuddy, D.: Eddy activity and phytoplankton distribution Sargasso Sea, summertime 2004. AGU Ocean Science meeting, Hawaii, USA, 2006.

Nicholson, D., Emerson, S., and Eriksen, C. C.: Net community production in the deep euphotic zone of the subtropical North Pacific gyre from glider surveys, Limnol. Oceanogr., 53, 22262236, 2008.

Nightingale, P. D., Malin, G., Law, C. S., Watson, A. J., Liss, P. S., Liddicoat, M. I., Boutin, J., and Upstill-Goddard, R. C.: In situ evaluation of air-sea gas exchange parameterizations using novel conservative and volatile tracers, Global Biogeochem. Cy., 14, 373-387, 2000.

Pacanowski, R. C. and Philander, S. G. H.: Parameterization of vertical mixing in numerical-models of tropical oceans, J. Phys. Oceanogr., 11, 1443-1451, 1981.

Painter, S. C., Sanders, R., Poulton, A. J., Woodward, E. M. S., Lucas, M., and Chamberlain, K.: Nitrate uptake at photic zone depths is not important for export in the subtropical ocean, Global Biogeochem. Cy., 21, GB4005, doi:10.1029/2006GB002807, 2007.

Paulson, C. A. and Simpson, J. J.: Irradiance measurements in upper ocean, J. Phys. Oceanogr., 7, 952-956, 1977.

Polzin, K. L., Toole, J. M., and Schmitt, R. W.: Finescale parame- 
terizations of turbulent dissipation, J. Phys. Oceanogr., 25, 306328, 1995.

Pomeroy, L. R. and Wiebe, W. J.: Energy sources for microbial food webs. Marine microbial food webs 7(1), 101-118., Mar. Microb. Food Webs, 7, 101-118, 1993.

Rees, A. P., Joint, I., Woodward, E. M. S., and Donald, K. M.: Carbon, nitrogen and phosphorus budgets within a mesoscale eddy: Comparison of mass balance with in vitro determinations, DeepSea Res. II, 48, 859-872, 2001.

Riser, S. C. and Johnson, K. S.: Net production of oxygen in the subtropical ocean, Nature, 451, 323-325, 2008.

Robinson, C., Serret, P., Tilstone, G., Teira, E., Zubkov, M. V., Rees, A. P., and Woodward, E. M. S.: Plankton respiration in the Eastern Atlantic Ocean, Deep-Sea Res. I, 49, 787-813, 2002.

Schmitt, R. W., Ledwell, J. R., Montgomery, E. T., Polzin, K. L., and Toole, J. M.: Enhanced diapycnal mixing by salt fingers in the thermocline of the tropical Atlantic, Science, 308, 685-688, 2005.

Sherr, E. B., Sherr, B. F., and Sigmon, C. T.: Activity of marine bacteria under incubated and in situ conditions, Aqua. Microb. Ecol., 20, 213-223, 1999.

Stanley, R. H. R., Jenkins, W. J., and Doney, S. C.: Quantifying seasonal air-sea gas exchange processes using noble gas timeseries: A design experiment, J. Mar. Res., 64, 267-295, 2006.
Stanley, R. H. R., Jenkins, W. J., Lott, D. E., and Doney, S. C.: Noble gas constraints on air-sea gas exchange and bubble fluxes, J. Geophys. Res., 114 C, doi:10.1029/2009JC005396, in press, 2009

Steinberg, D. K., Carlson, C. A., Bates, N. R., Johnson, R. J., Michaels, A. F., and Knap, A. H.: Overview of the US JGOFS Bermuda Atlantic Time-series Study (BATS): A decade-scale look at ocean biology and biogeochemistry, Deep-Sea Res. II, 48, 1405-1447, 2001.

Wanninkhof, R.: Relationship between wind-speed and gasexchange over the ocean, J. Geophys. Res., 97, 7373-7382, 1992.

Wanninkhof, R. and McGillis, W. R.: A cubic relationship between air-sea $\mathrm{CO}_{2}$ exchange and wind speed, Geophys. Res. Lett., 26, 1889-1892, 1999.

Williams, P. J. leB. and Purdie, D. A.: Invitro and insitu derived rates of gross production, net community production and respiration of oxygen in the oligotrophic subtropical gyre of the North Pacific-Ocean, Deep-Sea Res., 38, 891-910, 1991.

Williams, P. J. leB., Morris, P. J., and Karl, D. M.: Net community production and metabolic balance at the oligotrophic ocean site, station ALOHA, Deep-Sea Res. I, 51, 1563-1578, 2004.

Woolf, D. K. and Thorpe, S. A.: Bubbles and the air-sea exchange of gases in near-saturation conditions, J. Mar. Res., 49, 435-466, 1991. 